\section{BIRTH WEIGHT CLASSIFICATION IN GESTATIONAL DIABETES: IS THERE AN IDEAL CHART?}

Livia Silveira Mastella1 ${ }^{1}$, Letícia Schwerz Weinert ${ }^{1}$, Vanessa Gnielka², Vânia Naomi Hirakata ${ }^{3}$, Maria Lúcia Rocha Oppermann², Sandra Pinho Silveiro ${ }^{2}$, Angela Jacob Reichelt ${ }^{4}$

\section{ABSTRACT}

Introduction: Gestational diabetes mellitus (GDM) is associated to increased rates of large for gestational age (LGA) newborns and macrosomia. Several charts are used to classify birth weight. Is there an ideal chart to classify newborns of GDM mothers?

Postgraduate Program in Medical Science: Endocrinology, Universidade Federal do Rio Grande do Sul (UFRGS). Porto Alegre, RS, Brazil.

2 School of Medicine, Universidade Federal do Rio Grande do Sul (UFRGS). Porto Alegre, RS, Brazil.

3 Biostatistics Unit, Hospital de Clínicas de Porto Alegre (HCPA). Porto Alegre, RS, Brazil.

4 Endocrinology Division, Hospital de Clínicas de Porto Alegre (HCPA). Porto Alegre, RS, Brazil.

Corresponding author: Livia Silveira Mastella livia_mastella@yahoo.com.br Hospital de Clínicas de Porto Alegre Rua Ramiro Barcelos, 2350. 90035-003, Porto Alegre, RS, Brazil.
Methods: We evaluated adequacy of birth weight of 332 neonates born to GDM mothers at Hospital de Clínicas de Porto Alegre, Brazil. Newborns were classified according to gestational age as small (SGA), adequate, or large (LGA) based on four charts: Alexander, Pedreira, INTERGROWTH 21st Project, and SINASC-2012. The latter was built using data from a large national registry of 2012, the Born Alive National Surveillance System (Sistema de Informações de Nascidos Vivos - SINASC), which included 2,905.789 birth certificates. Frequencies of SGA and LGA and Kappa agreement were calculated.

Results: In non-gender adjusted curves, SGA rates (95\% confidence interval) varied from $8 \%(5-11)$ to $9 \%(6-13)$; LGA rates, from $11 \%(8-15)$ to $17 \%(13-21)$. For males, SGA rates varied from $3 \%(1-6 \%)$ to $6 \%(3-11 \%)$, and LGA rates, from $18 \%(13-24 \%)$ to $31 \%(24-38 \%)$; for females, SGA rates were from $3 \%(1-7 \%)$ to $10 \%(6-16 \%)$ and LGA rates, from $11 \%(6-16 \%)$ to $19 \%$ (13-26\%). Kappa results were: ALEXANDER vs. SINASC-2012: 0.80 (0.73-0.88); INTERGROWTH 21st vs. SINASC-2012 (adjusted by sex): 0.62 (0.53-0.71); INTERGROWTH 21st vs. PEDREIRA: 0.71 (0.62-0.79); SINASC-2012 (by sex) vs. PEDREIRA: 0.86 (0.79-0.93).

Conclusions: Misclassification has to be taken into account when evaluating newborns of GDM mothers, as LGA rates can almost double depending on the chart used to classify birth weight.

Keywords: Gestational diabetes; birth weight charts; large for gestational age newborn; small for gestational age newborn

Newborn birth weight classification according to gestational age is an important issue due to immediate and lifelong health consequences. For babies born too small, neonatal hypoglycemia, polycythemia, hyper viscosity ${ }^{1}$ and higher mortality are of immediate concern, whereas lifelong consequences include increased risk of ischemic heart disorders, diabetes, hypertension and chronic kidney disease ${ }^{2}$, as supported by the Barker's syndrome hypothesis ${ }^{3}$.

Conversely, those born bigger may have birth injury, hypoglycemia, icterus and prolonged hospitalization ${ }^{4}$. Moreover, they carry a higher risk of developing obesity in later life and type 2 diabetes ${ }^{5}$, in infants of diabetic mothers.

More than 100 curves relating birth weight and gestational age are available, most of them built upon regional or local registries ${ }^{6}$. The American Alexander's chart is our reference curve ${ }^{7}$, although one based on a large nationwide registry was suggested in the past ${ }^{8}$. In an attempt to unify newborn birth weight classification worldwide, a new chart was recently proposed ${ }^{6}$. It was constructed based on prospective data collected in eight "geographically 
defined urban populations" and included thousands of babies, with the intention of being endorsed by the World Health Organization.

Gestational diabetes mellitus (GDM) is a common cause of excessive birth weight, expressed either as large for gestational age (LGA) or as macrosomia ${ }^{9}$ (usually, defined as birth weight higher than 4,000 g). Recent meta-analyses described an increased rate of LGA and macrosomia for GDM women ${ }^{9,10}$, which can be decreased by treatment ${ }^{11}$ without increasing small for gestational age (SGA) rates ${ }^{11,12}$.

In this paper, our first objective was to plot a curve based on data from a large national registry of 2012 , the Born Alive National Surveillance System (Sistema de Informações de Nascidos Vivos - SINASC) ${ }^{13}$, creating the SINASC-2012 chart. The second objective was to compare newborn classification using four different birth weight curves applied to GDM pregnancies: Alexander chart ${ }^{7}$, Pedreira chart ${ }^{8}$, the INTERGROWTH 21st Project (INTERGROWTH 21st) chart $^{6}$ and finally, the new SINASC-2012 chart.

\section{METHODS}

From a cohort study described elsewhere ${ }^{14}$, we evaluated adequacy of birth weight of neonates born to gestational diabetes mothers. All pregnant women referred to the Hospital de Clínicas de Porto Alegre, a Brazilian university hospital that delivers tertiary care, from November 2009 to May 2013, were enrolled in the study. Gestational diabetes was diagnosed according to the Brazilian diagnostic criteria until 2010 ${ }^{15}$; after this year, GDM was diagnosed according to the IADPSG criteria ${ }^{16}$. Women were followed during the antenatal period by a multidisciplinary team, and delivered at the hospital. Birth weight was measured according to routine procedures - at the delivery room, after initial newborn care, without clothes - using a digital scale with weight range from $125 \mathrm{~g}$ to $15 \mathrm{~kg}$ and precision of $5 \mathrm{~g}$ (Filizola Baby ${ }^{\circledR}$ ).

In order to construct the SINASC-2012 curve, 2,905,789 birth certificates of Brazilian babies born in 2012 in the whole country were analyzed ${ }^{13}$. Valid cases were all single alive newborns delivered between 32-45 weeks of gestation, without gross malformations and whose mothers were between 15 and 40 years old. We excluded cases with missing information on fetal sex and babies weighing less than $702 \mathrm{~g}$ or more than $5,700 \mathrm{~g}$, resulting in $2,452,774$ newborns for analysis. The distributions of birth weight were built by gestational age and the 10th, 50th, and 90th percentiles were plotted at first irrespective of sex, and then stratified by gender. Newborns were classified as SGA if birth weight was
$<10$ th percentile for gestational age and as LGA if birth weight $>90$ th percentile.

We compared the cut points for the 10th, 50th and 90th percentiles of these newborns' weight with those of the reference curves. Except for the Alexander chart, birth weight was originally stratified by gestational age and sex in all others.

The four charts we compared were:

1) Alexander et al. ${ }^{7}$, an American chart that is reference in our hospital, classifies babies according to gestational age and is adjusted for sex only for the 10th percentile;

2) Pedreira et al. ${ }^{8}$, which was built based on $7,993,166$ certificates of birth weight from Brazilian babies delivered from 2003 to 2005 , with data plotted for 3-week intervals of gestational age, stratified by sex, with interpolation of calculated birth weights for the gestational ages in the intervals;

3) INTERGROWTH-21st ${ }^{6}$, intended to be the adopted by the World Health Organization;

\section{4) SINASC-2012 chart.}

Kappa statistic was used to evaluate agreement between different reference curves when applied to the GDM cohort. Agreement strength was classified as: <0.00, poor; $0.00-0.20$, slight; 0.21-0.40, fair; 0.41-0.60, moderate; 0.61-0.80, substantial; 0.81-1.00, almost perfect ${ }^{17}$. Analyses were performed with the SPSS 18 package; $95 \%$ confidence intervals $(95 \% \mathrm{Cl})$ were calculated with the WinPepi package ${ }^{18}$.

\section{RESULTS}

Data was available for 332 newborns of GDM women. Maternal age ranged from 16 to 46 years (mean $31 \pm 6$ years), 205 women $(62 \%)$ had a partner, $244(74 \%)$ referred white skin color, 238 (72\%) completed secondary school, 177 (53\%) had a first-degree history of diabetes, 298 (90\%) were non-smokers; $155(47 \%)$ were treated only with diet, $141(43 \%)$ had vaginal delivery, $13(4 \%)$ presented shoulder dystocia and $46(14 \%)$ of the women remained with some glucose abnormality after delivery. Macrosomia (birth weight $\geq 4,000 \mathrm{~g}$ ) occurred in 24 newborns (7.2\%) and low birth weight $(<2,500 \mathrm{~g})$ in $27(8.1 \%)$. Perinatal death occurred in 4 cases $(1.2 \%), 50(15.1 \%)$ had jaundice requiring phototherapy, 39 (9\%) had hypoglycemia requiring intensive care management, $53(16 \%)$ needed prolonged hospitalization after delivery (more than 5 days) and 14 (4\%) presented some malformation.

1) Results for objective 1 - Building the SINASC-2012 curve

Clinical characteristics of the 2,452.774 Brazilian pregnant women whose newborns' birth weight were 
used to construct the SINASC-2012 chart were: mean age, $26 \pm 6$ years (range 15-39 years); $57 \%$ had a partner, $79 \%$ had completed secondary school, $39 \%$ were white, $6 \%$ were black, $54.5 \%$ were an admixture of black and white, less than $1 \%$ were indigenous people or from oriental origin. Mean newborn weight was $3,226 \pm 486 \mathrm{~g}$ (range 705-5,730 g), with mean 1-minute Apgar score of $8 \pm 1$ and 5-minute Apgar score of $9 \pm 1$. Mean gestational age at delivery was $39 \pm 2$ weeks. Table 1 displays the 10 th, 50 th and 90th percentiles for each gestational age based on SINASC data ${ }^{13}$, both for the complete sample and according to sex.

2) Objective 2 - Evaluating SGA and LGA frequencies in GDM pregnancies

In Table 2 we present frequencies of SGA and LGA in the GDM cohort according to each chart. In some curves, birth weight was not set according to sex; therefore we further stratified analyses by newborn gender. The use of Alexander's and SINASC-2012

Table 1: SINASC-2012 chart: birth weight (g) according to gestational age for percentiles 10, 50 and 90 (total sample and stratified by sex).

\begin{tabular}{|c|c|c|c|c|c|c|c|c|c|c|}
\hline \multirow{2}{*}{$\begin{array}{l}\text { Gestational } \\
\text { week }\end{array}$} & \multirow[t]{2}{*}{$\mathbf{N}$} & \multicolumn{3}{|c|}{$\begin{array}{c}\text { 10th percentile } \\
(\mathrm{g})\end{array}$} & \multicolumn{3}{|c|}{$\begin{array}{c}\text { 50th percentile } \\
(\mathrm{g})\end{array}$} & \multicolumn{3}{|c|}{$\begin{array}{c}\text { 90th percentile } \\
(\mathrm{g})\end{array}$} \\
\hline & & Total & Male & Female & Total & Male & Female & Total & Male & Female \\
\hline 32 & 13728 & 1395 & 1445 & 1355 & 2135 & 2150 & 2110 & 3155 & 3165 & 3150 \\
\hline 33 & 21842 & 1650 & 1690 & 1605 & 2440 & 2445 & 2435 & 3300 & 3315 & 3290 \\
\hline 34 & 37546 & 1895 & 1934 & 1855 & 2655 & 2686 & 2625 & 3430 & 3460 & 3400 \\
\hline 35 & 62526 & 2125 & 2170 & 2090 & 2824 & 2865 & 2780 & 3580 & 3625 & 3510 \\
\hline 36 & 110225 & 2315 & 2350 & 2280 & 2920 & 2970 & 2870 & 3595 & 3635 & 3530 \\
\hline 37 & 242289 & 2520 & 2575 & 2475 & 3060 & 3115 & 3000 & 3650 & 3700 & 3580 \\
\hline 38 & 549044 & 2690 & 2745 & 2645 & 3190 & 3250 & 3125 & 3740 & 3800 & 3660 \\
\hline 39 & 680347 & 2780 & 2835 & 2735 & 3280 & 3340 & 3215 & 3828 & 3890 & 3750 \\
\hline 40 & 459549 & 2840 & 2900 & 2795 & 3360 & 3420 & 3300 & 3930 & 4000 & 3850 \\
\hline 41 & 181429 & 2850 & 2910 & 2800 & 3395 & 3460 & 3330 & 3985 & 4050 & 3900 \\
\hline 42 & 61065 & 2800 & 2850 & 2750 & 3350 & 3410 & 3287 & 3950 & 4010 & 3870 \\
\hline 43 & 22145 & 2790 & 2845 & 2730 & 3335 & 3400 & 3275 & 3910 & 3980 & 3845 \\
\hline 44 & 11039 & 2785 & 2850 & 2735 & 3340 & 3400 & 3270 & 3920 & 4000 & 3844 \\
\hline
\end{tabular}

Table 2: Adequacy of birth weight of 332 neonates born to GDM mothers according to four different charts.

\begin{tabular}{|c|c|c|c|c|c|}
\hline \multirow{3}{*}{ Birth weight chart } & $\mathbf{N}^{*}$ & SGA & $\%(95 \% \mathrm{Cl})$ & LGA & \multirow{3}{*}{$\%(95 \% \mathrm{Cl})$} \\
\hline & \multicolumn{4}{|c|}{ Original curves not divided by sex } & \\
\hline & \multicolumn{4}{|c|}{ Total sample } & \\
\hline Alexander et al. (1996) 7 & 332 & 31 & $9(6-13)$ & 37 & $11(8-15)$ \\
\hline \multirow[t]{2}{*}{ SINASC-2012* } & 332 & 25 & $8(5-11)$ & 55 & $17(13-21)$ \\
\hline & \multicolumn{4}{|c|}{ Male } & \\
\hline Alexander et al. (1996) ${ }^{7}$ & 178 & 11 & $6(3-11)$ & 27 & $15(10-21)$ \\
\hline \multirow[t]{2}{*}{ SINASC-2012 } & 178 & 7 & $4(2-8)$ & 40 & $22(17-29)$ \\
\hline & \multicolumn{4}{|c|}{ Female } & \\
\hline Alexander et al. (1996) ${ }^{7}$ & 154 & 20 & $13(8-19)$ & 10 & $6(3-12)$ \\
\hline \multirow{3}{*}{ SINASC-2012 } & 153 & 18 & $12(7-18)$ & 15 & $10(6-16)$ \\
\hline & \multicolumn{4}{|c|}{ Original curves divided by sex } & \\
\hline & \multicolumn{4}{|c|}{ Male } & \\
\hline Pedreira et al. (2011) ${ }^{8}$ & 178 & 6 & $3(1-7)$ & 32 & $18(13-24)$ \\
\hline SINASC-2012 & 178 & 11 & $6(3-11)$ & 33 & $19(14-26)$ \\
\hline \multirow[t]{2}{*}{ INTERGROWTH 21 $1^{\text {st }}(2014)^{6}$} & 177 & 5 & $3(1-6)$ & 54 & $31(24-38)$ \\
\hline & \multicolumn{4}{|c|}{ Female } & \\
\hline Pedreira et al. (2011) ${ }^{8}$ & 154 & 6 & $4(1-8)$ & 17 & $11(7-17)$ \\
\hline SINASC-2012 & 153 & 15 & $10(6-16)$ & 16 & $11(6-16)$ \\
\hline INTERGROWTH 21 st $^{\text {(2014) }}{ }^{6}$ & 151 & 4 & $3(1-7)$ & 29 & $19(13-26)$ \\
\hline
\end{tabular}

SGA: small for gestational age; LGA: large for gestational age; 95\%; CI: 95\% confidence interval. *SINASC-2012 (Table 1, present paper). 
curves resulted in similar rates of SGA, while LGA rates were more heterogeneous in the two curves not stratified by sex. The curves originally divided by sex showed similar rates of SGA for male and female newborns, except for females evaluated with the SINASC-2012 chart. In general, frequencies of LGA were $50 \%$ lower when applying the Alexander curve and not stratified by sex. In those originally divided by sex, LGA rates were consistently higher, almost twofold, in the INTERGROWTH-21st chart, for both newborn genders.

For male newborns, there were no differences of SGA frequencies, neither between the two Brazilian charts (SINASC-2012 6\% vs. Pedreira 3\%, $p=0.320$ ) nor for the comparison of the SINASC-2012 vs. INTERGROWTH 21 st ( $6 \%$ vs. $3 \%, p=0.200)$. Rates of LGA were different comparing the SINASC-2012 and the INTERGROWTH 21 st charts $(19 \%$ vs. $31 \%$,
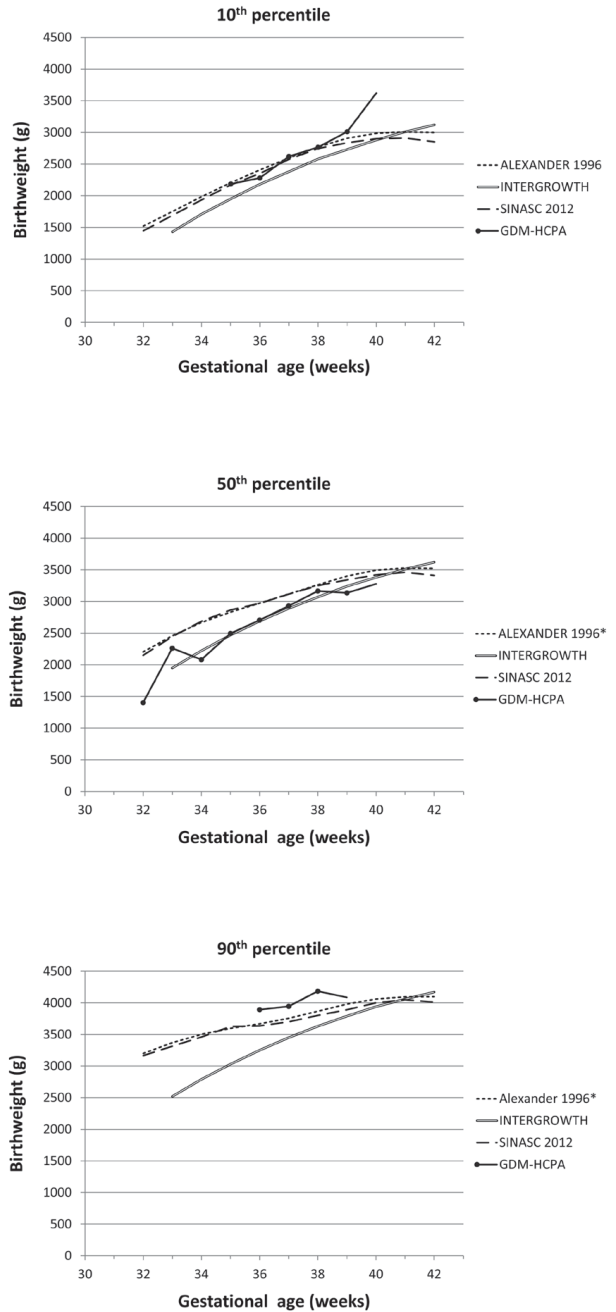

$\mathrm{p}=0.010$ ), but not when we compared SINASC-2012 and Pedreira (18\% vs. $19 \%, p>0.999)$.

For female newborns, rates of SGA were different between the Brazilian charts (SINASC-2012 10\% vs. Pedreira $4 \%, p=0.044$ ) as well as when comparing the SINASC-2012 with the INTERGROWTH 21st chart (SINASC-2012 10\% vs. INTERGROWTH 21st $3 \%, p=0.016)$. LGA rates were similar between the Brazilian charts (SINASC-2012 11\% vs. Pedreira 11\%, $p>0.999$ ) and different in the comparison between SINASC-2012 11\% vs. INTERGROWTH 21st 19\%, $p=0.036$. Birth weight percentiles of newborns delivered in GDM pregnancies, compared against the charts of Alexander, SINASC-2012 and INTERGROWTH 21st, are presented in Figure 1.

Kappa agreement results were substantially high or almost perfect in most of the comparisons (table 3). The lowest concordance was between the
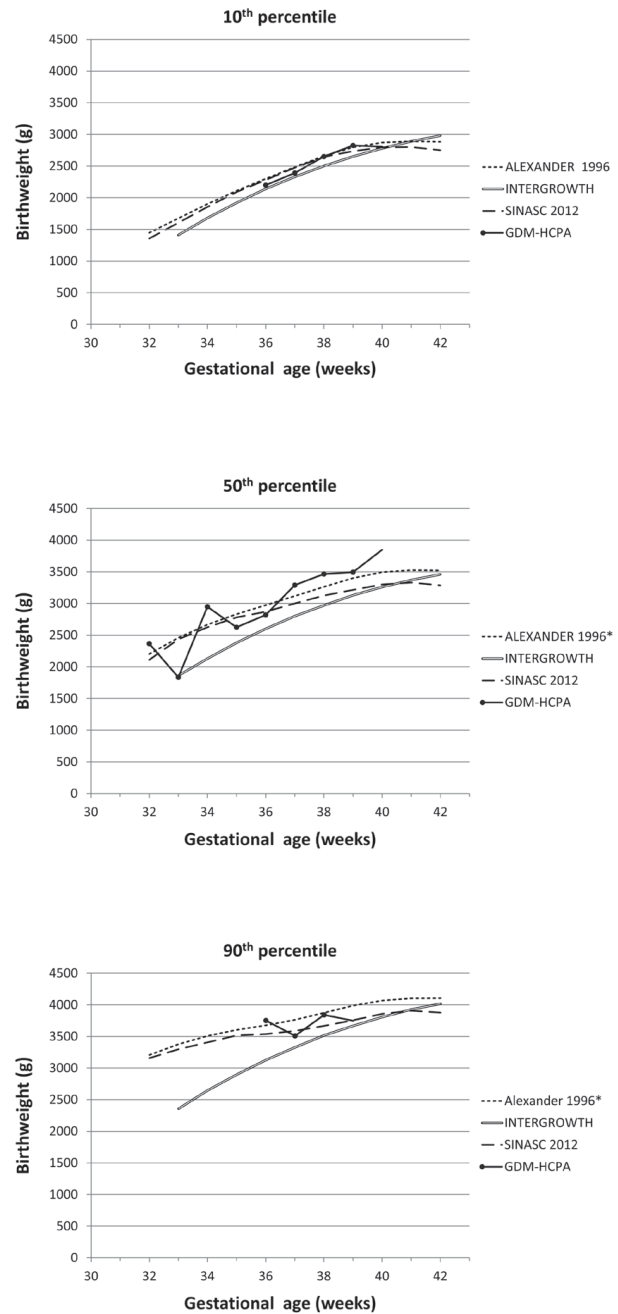

Figure 1: Birth weight percentiles in newborns of GDM women compared to standard birth weight curves. *Alexander (1996): newborn birthweight for percentiles $50^{\text {th }}$ and $90^{\text {th }}$ not divided by sex. Data from: Alexander ${ }^{7}$, Intergrowth $21^{\text {st }}$ Project $^{6}$ and SINASC-2012 (Table 1). 
Table 3: Kappa coefficient (95\% confidence interval) of selected newborn adequacy charts in GDM pregnancy.

\begin{tabular}{lcccccc}
\hline \multicolumn{1}{c}{ Comparison } & Total sample & $\mathbf{p}$ & Male & $\mathbf{p}$ & Female & $\mathbf{p}$ \\
\hline $\begin{array}{l}\text { ALEXANDER 1996 } \\
\text { vs. SINASC-2012 }\end{array}$ & $0.80(0.73-0.88)$ & 0.000 & $0.75(0.64-0.86)$ & 0.000 & $0.87(0.77-0.96)$ & 0.03 \\
$\begin{array}{l}\text { INTERGROWTH 21 } \\
\text { vs. SINASC-2012 (by sex) }\end{array}$ & $0.62(0.53-0.71)$ & 0.000 & $0.65(0.54-0,77)$ & 0.000 & $0.57(0.41-0.72)$ & $<0.001$ \\
$\begin{array}{l}\text { INTERGROWTH 21 } \\
\begin{array}{l}\text { st } \\
\text { vs. PEDREIRA }\end{array}\end{array}$ & $0.71(0.62-0.79)$ & 0.000 & $0.69(0.58-0.80)$ & 0.000 & $0.72(0.58-0.86)$ & 0.002 \\
$\begin{array}{l}\text { SINASC-2012 (by sex) } \\
\text { vs. PEDREIRA }\end{array}$ & $0.86(0.79-0.93)$ & 0.001 & $0.91(0.84-0.98)$ & 0.007 & $0.79(0.66-0.91)$ & 0.05 \\
\hline
\end{tabular}

INTERGROWTH-21st and both of the Brazilian curves. The best Kappa value was found for male newborns when we compared the two Brazilian curves.

\section{CONCLUSIONS}

In this cohort of 332 newborns from GDM pregnancies, frequencies of SGA and LGA varied considerably according to the chart used. SGA rates were very low for both male $(2.8 \%)$ and female newborns $(2.6 \%)$ when using the international INTERGROWTH-21st chart. LGA frequencies can almost double, depending on the chosen chart, from $\sim 18 \%$ to $\sim 30 \%$ in male and from $\sim 11 \%$ to $\sim 19 \%$ in female newborns.

Rates of male SGA newborns were similar for the two charts based on national registries, even considering that the first one was built upon data collected more than 10 years ago, and grouped gestational age at three-week intervals ${ }^{8}$. In female newborns, an unexpectedly higher rate of SGA was found when applying the contemporary curve, SINASC-2012, compared to the late Pedreira, a finding we could not thoroughly clarify herein because we did not adjust frequencies to potential confounders like smoking or hypertension in pregnancy. One explanation could be that the frequency of these confounders might have increased along time, negatively affecting birth weight.

LGA rates were similar between the two Brazilian curves, but significantly higher when we applied the international INTERGROWTH-21st curve ${ }^{6}$ both for male and female babies, raising the question that maybe an international chart might prove itself difficult to be adopted due to this kind of difference.

Why is birth weight classification in GDM a matter of concern? First, it was recently suggested that, in order to compare different studies on the subject, standardized outcome definitions would be necessary ${ }^{19}$. In a systematic review, 19 different definitions were used to classify large for gestational age, thus leading to 19 possible different results and study conclusions ${ }^{19}$. Different charts could further complicate the interpretation of those rates, as birth weight classification cut points for the same gestational age can be very different among them. Besides outcome definitions, another problem was recently raised by a German group: plotting errors could cause a "leftward shift" on the curves, raising SGA and diminishing LGA rates, thus potentially misclassifying around $5 \%$ of the babies ${ }^{20}$. Second, meta-analyses described an increased risk of macrosomia and LGA in women with gestational diabetes ${ }^{9,10}$, irrespective of the diagnostic criteria. Three other meta-analyses showed consistent benefits of GDM treatment, with protective effects concerning LGA and macrosomia, without increasing SGA rates ${ }^{11,12,21}$. As an obvious consequence of the most employed definitions, SGA and LGA frequencies are expected to be $10 \%$ each. In non-treated GDM pregnancies, Wendland et al. reported a LGA incidence of $14.5 \%$ in 3054 women when 1999-WHO criteria were used, with a relative risk (RR) of $1.81(95 \% \mathrm{Cl} 1.47-2.22)$ and of $15.4 \%$ in 6201 women with the IADPSG criteria (RR 1.38 95\% Cl 1.14-1.68) ${ }^{9}$, compared to non-GDM women. Treatment of GDM significantly reduces LGA rates without increasing the risk of SGA babies ${ }^{12}$. The frequency of LGA was $14.8 \%$ of 2245 women in a meta-analysis including four treatment studies; based on three studies, the frequency of SGA was $7 \%{ }^{11}$. In a large American cohort of treated GDM women $(n=7,468)$, the frequency of LGA adjusted for maternal age varied from $13.9 \%$ in Asian women, to $25.1 \%$ in African-American women, and reached frequencies higher than $20 \%$ in obese women when further adjusted to BMI, in all racial groups ${ }^{22}$. Third, classification of babies carries some prognostic implications, both in short- and long-term; therefore, misclassification could lead to potential mistreatment or overtreatment ${ }^{1,20}$. For example, a low birth weight $(<2,500 \mathrm{~g})$ could imply an increased risk of mortality and of neurological morbidities ${ }^{23}$.

In an attempt to standardize newborn charts, the INTERGROWTH- $21^{\text {st }}$ project prospectively evaluated more than 20,000 women for four years and sex-specific curves for weight, length and head circumference according to gestational age at delivery were plotted. The authors concluded that the development of 
"international anthropometric standards to assess newborn size that are intended to complement the WHO Child Growth Standards" would "allow comparisons across multiethnic populations"6. Unexpectedly, in our cohort, the use of the INTERGROWTH $21^{\text {st }}$ charts almost doubled rates of LGA newborns, both male and female, indicating that, at least for babies born to GDM women, an increased rate of large newborns can be expected when adopting the international standard. Conversely, significantly lower rates of SGA would be found for female SGA newborns with this new chart.

Alternatives to overcome these problems must be sought. Several authors suggest the adoption of specific curves for each population group ${ }^{24-26}$. Other possibility would be to consider only extremes of weight as cut points, such as macrosomia (either $>4,000 \mathrm{~g}$ or $>4,500 \mathrm{~g}$ ) or low birth weight $(<2,500 \mathrm{~g}$ or even $<1,500 \mathrm{~g}$ ). At least for low birth weight, absolute weight was more accurate than percentiles to predict neonatal adverse outcomes ${ }^{23}$. In our cohort, around $7 \%$ of babies would be labeled as macrosomic $(>4,000 \mathrm{~g})$, compared to $14.5 \%$ observed in a meta-analysis of six experimental studies on GDM treatment ${ }^{11}$. This outcome was considered as being of "critical importance" by the authors ${ }^{11}$.

Scarce information exists on low birth weight occurrence in GDM, as this is not an expected outcome. Maternal hyperglycemia, the hallmark of GDM, leads to fetal hyperinsulinism and overgrowth, therefore being associated to the delivery of LGA babies $^{27}$. Nevertheless, SGA frequency was around $7 \%$ in the above meta-analysis ${ }^{11}$, similar to our own rate $(8.1 \%)$.

One of the strengths of our study was the number of newborns of GDM women employed for the evaluation of several birth weight charts. A second point was the possibility of building a national curve, which, to our knowledge, is the first one with sequential birth weight values for each gestational week after week 32. It included a large number of babies and, as it was generated from a large national database, it is representative of the birth weight pattern across the country.
Limitations of the study would be the scarce numbers of birth weight values in extremes of gestational age and the inclusion of GDM women with two different diagnostic criteria. Regarding the latter point, analysis of maternal clinical baseline characteristics and of the main fetal and neonatal outcomes did not disclose differences between both criteria. An important limitation of the SINASC-2012 chart relates to inconsistencies of birth weight values in early gestational ages, probably due to errors or incompleteness of data transcription. A bimodal pattern of birth weight distribution at lower gestational ages was found in our preliminary analyses, thus precluding the assignment of birth weight values for gestational ages lower than 32 weeks. Potential errors in the SINASC registries were previously described ${ }^{28}$. Coverage was in general adequate, more than $90 \%$; greater inconsistency was found for "the mother's educational level, number of prior childbirths and frequency of prenatal visits" 28 ; information regarding parity was the most incomplete, but there was no description of an eventual bimodal distribution of birth weight in earlier pregnancy ages ${ }^{28}$. Another potential limitation of our curve would be plotting errors, as described above ${ }^{20}$.

In conclusion, the adoption of different charts to classify newborn birth weight can lead to different rates of SGA and LGA babies in GDM pregnancies. The adoption of an international standard implies a higher, almost twice, LGA frequency and, in female babies, lower SGA frequencies. Strategies to improve birth weight classification to avoid misclassification of babies born to GDM mothers must be sought. Perhaps an internationally accepted birth weight chart, and, furthermore, the adoption of an international diagnostic criterion for GDM, would improve power and quality of studies on GDM management, as well as birth weight classification, worldwide.

\section{Acknowledgements}

Funding: Fundo de Incentivo à Pesquisa e Eventos (FIPE-HCPA), Project n. 10-0364.

\section{REFERENCES}

1. Das UG, Sysyn GD. Abnormal fetal growth: intrauterine growth retardation, small for gestational age, large for gestational age. Pediatr Clin North Am. 2004;51(3):639-54, viii. PMid:15157589. http://dx.doi. org/10.1016/j.pcl.2004.01.004.

2. Saenger $P$, Czernichow $P$, Hughes $I$, Reiter EO. Small for gestational age: short stature and beyond. Endocr Rev. 2007;28(2):219-51. PMid:17322454. http://dx.doi.org/10.1210/er.20060039.

3. Barker DJ. Fetal origins of cardiovascular disease. Ann Med. 1999;31(Suppl 1):3-6. PMid:10342493.
4. Henriksen T. The macrosomic fetus: a challenge in current obstetrics. Acta Obstet Gynecol Scand. 2008;87(2):134-45. PMid:18231880. http://dx.doi. org/10.1080/00016340801899289.

5. Metzger BE. Long-term outcomes in mothers diagnosed with gestational diabetes mellitus and their offspring. 
Clin Obstet Gynecol. 2007;50(4):9729. PMid:17982340. http://dx.doi. org/10.1097/GRF.0b013e31815a61d6.

6. Villar J, Ismail LC, Victora CG, Ohuma EO, Bertino E, Altman $D G$, et al. International standards for newborn weight, length, and head circumference by gestational age and sex: the Newborn Cross-Sectional Study of the INTERGROWTH-21st Project. Lancet. 2014;384(9946):85768. PMid:25209487. http://dx.doi. org/10.1016/S0140-6736(14)60932-6.

7. Alexander GR, Himes JH, Kaufman RB, Mor J, Kogan M. A United States national reference for fetal growth. Obstet Gynecol. 1996;87(2):1638. PMid:8559516. http://dx.doi. org/10.1016/0029-7844(95)00386-X.

8. Pedreira CE, Pinto FA, Pereira SP, Costa ES. Birth weight patterns by gestational age in Brazil. An Acad Bras Cienc. 2011;83(2):61925. PMid:21625798. http:// dx.doi.org/10.1590/S000137652011005000008 .

9. Wendland EM, Torloni MR, Falavigna M, Trujillo J, Dode MA, Campos MA, et al. Gestational diabetes and pregnancy outcomes-a systematic review of the World Health Organization (WHO) and the International Association of Diabetes in Pregnancy Study Groups (IADPSG) diagnostic criteria. BMC Pregnancy Childbirth. 2012;12(1):23. PMid:22462760. http://dx.doi. org/10.1186/1471-2393-12-23.

10. Hartling L, Dryden DM, Guthrie A, Muise M, Vandermeer B, Donovan L. Diagnostic thresholds for gestational diabetes and their impact on pregnancy outcomes: a systematic review. Diabet Med. 2014;31(3):31931. PMid:24528230. http://dx.doi. org/10.1111/dme.12357.

11. Falavigna M, Schmidt MI, Trujillo J, Alves LF, Wendland ER, Torloni $M R$, et al. Effectiveness of gestational diabetes treatment: a systematic review with quality of evidence assessment. Diabetes Res Clin Pract. 2012;98(3):396-405. PMid:23031412. http://dx.doi.org/10.1016/j. diabres.2012.09.002.

12. Hartling L, Dryden DM, Guthrie A, Muise M, Vandermeer B, Donovan L. Benefits and harms of treating gestational diabetes mellitus: a systematic review and meta-analysis for the U.S. Preventive Services Task Force and the National Institutes of Health Office of Medical Applications of Research. Ann Intern Med. 2013;159(2):123-9. PMid:23712381. http://dx.doi.org/10.7326/0003-4819159-2-201307160-00661.

13. Brasil. Ministério da Saúde. Secretaria de Vigilância em Saúde. Coordenação Geral de Informações e Análises Epidemiológicas - CGIAE. Consolidação do Sistema de Informações sobre Nascidos Vivos - 2011. Brasília, DF: Ministério da Saúde; 2013. [cited 2016 October 1]. Available from: http://tabnet.datasus. gov.br/cgi/tabcgi.exe?sinasc/cnv/nvuf. def\%5D.

14. Weinert LS, Reichelt AJ, Schmitt LR, Boff R, Oppermann ML, Camargo $\mathrm{JL}$, et al. Serum vitamin D insufficiency is related to blood pressure in diabetic pregnancy. Am J Hypertens. 2014;27(10):1316-20. PMid:24663440. http://dx.doi.org/10.1093/ajh/hpu043.

15. Reichelt AJ, Oppermann MLR, Schmidt MI. Recomendações da 2a. Reunião do Grupo de Trabalho em Diabetes e Gravidez. Arq Bras Endocrinol Metabol. 2002;46(5):57481. http://dx.doi.org/10.1590/S000427302002000500012.

16. Metzger BE, Gabbe SG, Persson B, Buchanan TA, Catalano PA, Damm $P$, et al. International association of diabetes and pregnancy study groups recommendations on the diagnosis and classification of hyperglycemia in pregnancy. Diabetes Care. 2010;33(3):676-82. PMid:20190296. http://dx.doi.org/10.2337/dc09-1848.

17. Landis JR, Koch GG. The measurement of observer agreement for categorical data. Biometrics. 1977;33(1):159-74. PMid:843571. http://dx.doi.org/10.2307/2529310.

18. Abramson JH. WINPEPI updated: computer programs for epidemiologists, and their teaching potential. Epidemiol Perspect Innov. 2011;8(1):1. PMid:21288353. http:// dx.doi.org/10.1186/1742-5573-8-1 .

19. Feig DS, Corcoy R, Jensen DM, Kautzky-Willer A, Nolan CJ, Oats $\mathrm{JJ}$, et al. Diabetes in pregnancy outcomes: a systematic review and proposed codification of definitions. Diabetes Metab Res Rev. 2015;31(7):680-90. PMid:25663190. http://dx.doi.org/10.1002/dmrr.2640.

20. Rochow N, Raja P, Straube S, Voigt $M$. Misclassification of newborns due to systematic error in plotting birth weight percentile values. Pediatrics. 2012;130(2):e347-51. PMid:22826576. http://dx.doi.org/10.1542/peds.20113884.

21. Horvath K, Koch K, Jeitler K, Matyas E, Bender R, Bastian H, et al. Effects of treatment in women with gestational diabetes mellitus: systematic review and meta-analysis. $B M J$. 2010;340:c1395. PMid:20360215. http://dx.doi.org/10.1136/bmj.c1395.

22. Sridhar SB, Ferrara A, Ehrlich SF, Brown SD, Hedderson MM. Risk of large-for-gestational-age newborns in women with gestational diabetes by race and ethnicity and body mass index categories. Obstet Gynecol. 2013;121(6):1255-62. PMid:23812460. http://dx.doi.org/10.1097/ AOG.0b013e318291b15c.

23. Malin GL, Morris RK, Riley R, Teune MJ, Khan KS. When is birthweight at term abnormally low? A systematic review and meta-analysis of the association and predictive ability of current birthweight standards for neonatal outcomes. BJOG. 2014;121(5):515-26. PMid:24397731. http://dx.doi.org/10.1111/14710528.12517.

24. Kramer MS, Platt RW, Wen SW, Joseph KS, Allen A, Abrahamowicz $M$, et al. A new and improved population-based Canadian reference for birth weight for gestational age. Pediatrics. 2001;108(2):E35. PMid:11483845. http://dx.doi. org/10.1542/peds.108.2.e35.

25. Talge NM, Mudd LM, Sikorskii A, Basso O. United States birth weight reference corrected for implausible gestational age estimates. Pediatrics. 2014;133(5):844-53. PMid:24777216. http://dx.doi.org/10.1542/peds.20133285.

26. Ray JG, Sgro M, Mamdani MM, Glazier RH, Bocking A, Hilliard $\mathrm{R}$, et al. Birth weight curves tailored to maternal world region. $J$ Obstet Gynaecol Can. 2012;34(2):15971. PMid:22340065. http://dx.doi. org/10.1016/S1701-2163(16)35159-3.

27. Freinkel N, Metzger BE. Pregnancy as a tissue culture experience: the critical implications of maternal metabolism for fetal development. Ciba Found Symp. 1978;(63):3-28. PMid:378621.

28. Pedraza DF. Quality of the Information System on Live Births /SINASC: a critical analysis of published studies. Cien Saude Colet. 2012;17(10):272937. PMid:23099759. http:// dx.doi.org/10.1590/S141381232012001000021. 